\title{
Woerlee Responds
}

To the Editor:

I thank Dan Punzak and Oral Ford for their responses to my recent article in this Journal (Woerlee, 2004).

In response to Punzak's comments, first I would like to clarify the differences between cardiologists and anesthesiologists. Both are doctors specialized in different aspects of medicine. The anesthesiologist is by virtue of his profession specialized in many practical aspects of cardiology. Often he must keep patients with failing hearts alive during operations, despite the depressant effects of anesthetic drugs upon the heart, the loss of blood due to the operation, and the pain due to the surgery - and all this is done with the full gamut of cardiological therapies and monitoring. This is my normal work, and that of many anesthesiologists working in large and moderately large hospitals. (See my website page on anesthesia for a simple and clear description of the effects of anesthesia and the tasks of the anesthesiologist written for non-medical persons: www.mortalminds.org.)

As an anesthesiologist, I am a member of the hospital resuscitation team and regularly take part in resuscitation of patients in the hospital, as well as occasionally in operating rooms with patients who develop cardiac arrests during operations. Furthermore, I teach the basics of physiology as applied to anesthesia to physicians specializing in anesthesia, which includes extensive teaching about the mechanisms and effects of oxygen starvation, a matter of vital of concern to all anesthesiologists (chapter 16 in Woerlee [2003] contains an extensive review of the effects of oxygen starvation on humans 
together with extensive references to appropriate human research). Regarding cardiological problems, I have written textbooks covering cardiological aspects of body function affecting patient survival (Woerlee, 1988), as well as the way heart function influences the mathematical description of drug distribution and actions in the body, (Woerlee 1992, 2005).

There are very good reasons I did not consider the research of Michael Sabom. Sabom is a cardiologist who has done much to further the serious study of near-death experiences (NDEs), and the study in his book is quite good, but it only deals with retrospective NDE accounts (Sabom, 1982). They are accounts of NDEs told by those who underwent them some time after the events related. These NDE accounts were related to Sabom at periods varying from one day to many years after the NDEs occurred. Such retrospective studies are always tainted to some degree by alterations in memory, as well as an unconscious desire to embellish.

The study of Pim van Lommel and his colleagues was quite different (Van Lommel, Van Wees, Meyers, and Elfferich, 2001). It was set up with a strict protocol whereby survivors of cardiac arrest and resuscitation in participating hospitals were administered a standard interview a few days, two years, and eight years after the event. This minimized the problems of possible embellishment, giving the best chance of an accurate account of the incidents and the experiences undergone. This study was excellent, but I disagree with the interpretation of the causes of the NDE proposed by Van Lommel and his co-workers, because the functioning of the human body and natural laws both explain and predict all aspects of the NDEs reported in this study (Woerlee, 2004; see also Woerlee [2003] for extensive explanations of all NDE phenomena reported by Sabom).

This brings us to the person of the pseudonymous Pam Reynolds. Her story has achieved an almost hagiographic status in the world of popular near-death literature (Sabom, 1998). It is an account of a truly profound and wondrous NDE, but nonetheless an account whose every aspect can be explained by natural laws, the functioning of the human body, and the effects of anesthesia. I have administered anesthesia for such neurosurgical procedures for several years, and am very familiar with the techniques and surgical instruments used at the time of her operation; they are standard in all advanced Western countries. I am also very familiar with the technique of hypothermic cardiac arrest used during this operation, having done a residency in the Westminster Hospital during 1979-1980 in London, England, where the 
cardiothoracic surgeon Charles Drew was still using this technique for heart surgery in adults (Hilson, 2001). There I was one of the last few residents to get experience with hypothermic cardiac arrest at body temperatures down to $12^{\circ} \mathrm{C}\left(54^{\circ} \mathrm{F}\right)$. At these temperatures the heart no longer beat, the circulation ceased, we stopped mechanical ventilation, and Drew then had about 45 minutes to perform his operation before brain damage started to occur in these so-called "clinically dead" persons. So I am also quite familiar with the technique of hypothermic cardiac arrest.

I have written an extensive two-part article for the British magazine The Skeptic, detailing how Reynolds' body could generate her amazing NDE. A short preliminary version of this article is to be found on the appropriate page of my website at www.mortalminds.org. For some reason, many people seem to ignore the accurate sequence of events surrounding the timing of the operative events. I will give them here in the form of a list that clarifies Reynolds' story considerably.

First, Reynolds was put under general anesthesia.

Second, Reynolds' head was clamped onto the operating table.

Third, Reynolds' head was disinfected and her body was covered with surgical drapes, except for those parts of the head the surgeon wanted to operate upon, and the groin where the cardiothoracic surgeon was to insert the bypass tubing into the large blood vessels there.

Fourth, Robert Spetzler, the neurosurgeon, cut open the skin of the scalp, and drilled a hole in the skull with a pneumatic drill so as to insert the pneumatic bone saw.

Fifth, Reynolds awakened to the sound of the bone saw, which she later described as a "high D." She was awake because of insufficient anesthesia (see my web page on anesthesia), and unable to move because of paralysis caused by anesthetic drugs.

Sixth, vibrations from the pneumatic saw together with the effects of anesthetic drugs induced an out-of-body experience (OBE) (see chapter 12 in Woerlee, 2003).

Seventh, she perceived all that happened in the operating room during her OBE.

Eighth, she heard the voice of the cardiothoracic surgeon saying that the blood vessels on one side of her body were too small to insert the cardiac bypass tubing, and that she would have to use the veins on the other side. This means Reynolds was not on bypass, and that her body was not cooled down at this point. In fact, to cool her body down to $15^{\circ} \mathrm{C}$ without cardiac bypass would have caused her heart to stop beating, and most likely her death. 
Ninth, bypass tubing was inserted as the operation progressed.

Tenth, Reynolds' body was gradually cooled down by cooling the blood passing through the cardiac bypass pump, but not to less than $32^{\circ} \mathrm{C}$; otherwise cardiac arrest or other forms of abnormal heartbeat were likely to occur.

Eleventh, the aneurysm was exposed. Reynolds' body was then definitively cooled to $15^{\circ}$, her heart stopped beating, and blood was drained from her head. The neurosurgeon now had 40 to 45 minutes to operate on the aneurysm and restore circulation before brain damage started to occur.

Twelfth, the aneurysm was successfully operated on.

Thirteenth, the cardiac bypass pump warmed the blood passing through it, raising Reynolds' body temperature back to normal.

Fourteenth, normal heart action was restored with a defibrillator, causing her body to arch upwards due to the 5000-volt, high-amperage shock delivered by the defibrillator.

Sixteenth, the operation was finished to the tune of "Hotel California," but even though Reynolds was awake at the time, she could not move because she was still paralyzed due to paralyzing drugs.

Her typically American transcendental NDE of someone expecting to die (see the page on NDE types in my website) occurred somewhere between the time of her OBE and the awakening at the end of the operation. But it could not have occurred during her period of hypothermic cardiac arrest, because people are definitely unconscious at $15^{\circ} \mathrm{C}$, and unconscious people have no conscious experiences.

I believe this clarifies the opinions expressed in my article in this Journal, clarifies my opinion regarding Reynolds' story, and hopefully answers Punzak's question.

In response to Ford's comments, he raised a large number of points as proof of his thesis that the mind is something quite separate from the body. This concept of an immaterial mind that is separate from the body has existed throughout all known human history, but is, in my opinion, a concept totally at variance with medical reality. True, it is a very believable and emotionally very satisfying idea, but it is an idea whose origin lies in the functioning of the human body. I have found no evidence to the contrary.

By profession and training I am a physician specialized in anesthesiology, a profession in which I am still very active. Accordingly, my approach to the problem of determining whether consciousness is generated by the physical brain or a product of an 
external influence whose effects are mediated through the brain is medical, not philosophical, not emotional, but simply based upon the facts of body function. An extensive study of the relationship of the body to the mind reveals the impossibility of definitively proving whether brain mechanisms generate consciousness and mind, or whether the brain is the receiver of consciousness and all other properties of mind from an external source. Regardless of which of these two possibilities is true, one fact stands out - a fact born out by observations made by each and every person, and especially by anesthesiologists: consciousness and all properties of mind require the mechanisms of the brain and the body to manifest. I will give a short exposé of my reasoning.

A simply enormous amount of research performed over the last 50 to 60 years reveals that the manifestation of consciousness requires an intact and functioning upper brainstem. A person whose upper brainstem is destroyed or malfunctions is unconscious. This is a fact with which I am regularly confronted. All the belief and willpower in the world cannot alter this. An example of this is the effect of drugs used to induce sleep at the beginning of a general anesthetic. These drugs act by causing brainstem malfunction, thereby causing the patient to lose consciousness. Some patients tell me they do not believe that the contents of the syringe containing these sleep-inducing drugs will cause them to lose consciousness. They try and try their very best not to lose consciousness, summoning all the willpower they possess, but 20 to 30 seconds after the drug is administered into a hand or arm vein, it arrives in the blood passing through the brainstem, diffuses into the substance of the brainstem, and causes the cells there to malfunction, thereby inducing unconsciousness. This means an intact and functioning brainstem is required to generate, or to manifest, consciousness.

The fact that a person is unconscious due to any cause, such as sleep, general anesthesia, a blow on the head, or whatever does not mean the rest of the brain malfunctions. Many years of research show that the brains of unconscious people are capable of registering and processing sensory inputs while unconscious. A nice example of this is a phenomenon called implicit learning. Patients under general anesthesia hear a sequence of words spoken out aloud by the researcher. After awakening, they are asked to recognize words that sound familiar, and more often than not they choose the words spoken into their ears while under general anesthesia. There are many more examples of this type of unconscious mental processing. But all these 
things and processes have one thing in common: the parts of the brain involved in registering, processing, and remembering these stimuli must be intact and functioning, otherwise the brain cannot generate the appropriate responses, or manifest the appropriate responses.

Then we come to the matter of movements. Clinical experience reveals a number of facts, some of them very strange indeed.

First, a spinal anesthetic is a form of local anesthesia of the whole of the lower part of the body, blocking transmission of nerve impulses from the brain to the lower body, and blocking all sensory impulses transmitted from the lower body to the brain. If the leg of a person under spinal anesthesia is lifted so that the person can see the leg, that person almost always exclaims, "Is that my leg?" Persons undergoing spinal anesthesia feel the leg is in some totally different position, or the idea of the leg has disappeared from their minds altogether. When they try to move their legs, they find they cannot move their legs, and even the use of incredible willpower fails to elicit movements - proof that the mind must use the mechanisms of the body to manifest.

Second, a person who suffers a stroke of the right parietal lobe without involvement of the motor cortex has what is called left-sided neglect. Such persons claim nothing is wrong with their body, but act as if the left-hand side of their body was paralyzed, even though painful and other stimuli applied to the left-hand side of the body elicit movements, proving that the left-hand side is not paralyzed. When asked to draw a clock face, or a figure of a human body, people with left-sided neglect only draw the right-hand side of the clock face, or the right-hand side of their body. This indicates that the mechanisms of the brain must be present to generate the idea of the left-hand side of the body, or that the same mechanisms must be present to manifest the effects of a mind influencing the body.

Third, disease or damage of the hippocampus causes failure of generation of long-term memory. The cells of the CA1 sector of the hippocampus are exquisitely sensitive to oxygen starvation, and elderly people may have failure of this aspect of hippocampal function due to brain oxygen starvation caused by diseased brain blood vessels commonly affecting the elderly. This is why the elderly can remember the past very well, but are not so good at remembering recent events.

Fourth, the neurological and anesthesiological literature are full of many more such examples, as well as examples of how drugs, physiological states, and so on, can alter mental state.

Now we come to the matter of altered states of consciousness. Consciousness is a condition that is either present or absent. But the 
state of consciousness can be modulated by the physiological or psychological state of a person, drugs, hormones, oxygen starvation, epilepsy, many brain diseases, brain malfunction, or actual brain damage. These are the basic modulators of the state of consciousness, and these explain altered states of consciousness.

All these considerations still do not enable a determination of whether brain mechanisms generate consciousness and mind, or whether the brain is the receiver of consciousness and all other properties of mind. However these considerations do prove conclusively that the physical mechanisms of the brain are required to generate the properties of the mind, or to manifest the properties of the mind.

So is the mind something immaterial and independent of the body, or are all properties of consciousness and mind generated by the brain and modulated by the body? As of yet, it is impossible to distinguish between these two possibilities solely by examining the properties of the mind. Something more is needed, and this means investigating the properties of a possible immaterial mind.

But it is impossible to examine something immaterial directly, because it is just that: immaterial. Accordingly, the only way to investigate the properties of a possibly immaterial mind is to examine known indirect evidence for the immaterial, such as is manifested by auras, paranormal phenomena, NDEs, OBEs, demonic attack, and so on. Yet the very immaterial nature of these phenomena also makes them impossible to investigate directly. So all that can be done is to carefully determine the properties of these phenomena, and see if they can be predicted and explained by physical explanations, which in turn are capable of yielding predictions of the observed nature of these phenomena. Such a methodology reveals that the human aura, paranormal phenomena, OBEs, NDEs, and stories of nocturnal demonic attack are all explicable in terms of natural laws and the functioning of the human body (Woerlee, 2003). Furthermore, it is possible to make useful predictions about the properties of these phenomena with these natural, physical, and biological explanations. It is true that explanations using natural laws and the functioning of the human body to explain these phenomena do not exclude the possibility of the immaterial, including the possibility of an immaterial mind. But when not one, not two, nor three, but each and every one of these phenomena can be explained in this way, then the chance of these phenomena being due to something immaterial acting from outside the body, or independent of the body, becomes vanishingly small. 
All this means that the paranormal and the immaterial very likely do not exist, that is very likely that there is no immaterial soul, no reincarnation, just the wonder of the physical universe we inhabit with our very mortal and physical bodies, the generators of our consciousness and minds.

All this is a rather different way of looking at things than in Ford's thesis. For a more extensive discussion replete with references to the fundamental medical research, I refer readers to my book, Mortal Minds: A Biology of the Soul and the Dying Experience (2003).

\section{References}

Hilson, A. (2001). Charles Drew's profound hypothermia apparatus. Lancet, 358, 1650.

Sabom, M. B. (1982). Recollections of death: A medical investigation. New York, NY: Harper and Row.

Sabom, M. B. (1998). Light and death: One doctor's fascinating account of near-death experiences. Grand Rapids, MI: Zondervan.

Van Lommel, P., Van Wees, R., Meyers. V., Elfferich, I. (2001), Near-death experience in survivors of cardiac arrest: A prospective study in the Netherlands. Lancet, 358, 2039-2045.

Woerlee, G. M. (1988). Common perioperative problems and the anaesthetist. Dordrecht, The Netherlands: Kluwer.

Woerlee, G. M. (1992). Pharmacokinetics of intravenous anaesthetics. Dordrecht, The Netherlands: Kluwer.

Woerlee, G. M. (2003). Mortal minds: A biology of the soul and the dying experience. Utrecht, The Netherlands: de Tijdstroom. (This book will also be published in 2005 in Buffalo, NY, by Prometheus Books under the title Mortal minds: The biology of neardeath experiences.)

Woerlee, G. M. (2004). Cardiac arrest and near-death experiences. Journal of NearDeath Studies, 22, 235-249.

Woerlee, G. M. (2005). Gerry's real world guide to phamacokinetics and other things. Leicester, England: Matador.

G. W. Woerlee, M.B.B.S., F.R.C.A. Kagerstraat 4 2334CR Leiden The Netherlands

E-mail: mortalminds@hotmail.com 